\title{
New Optimization Strategy for Design of Active Twist Rotor
}

\author{
Devesh Kumar* and Carlos E. S. Cesnik \\ University of Michigan, Ann Arbor, Michigan 48105
}

DOI: $\underline{10.2514 / 1 . J 053195}$

\begin{abstract}
This paper presents the development of a mixed-variable optimization framework for the aeroelastic analysis and design of active twist rotors. Proper tailoring of the blade properties can lead to the maximization of the active twist and the control authority for vibration reduction under operating conditions. Thus, using mathematical optimization, the cross-sectional layout is designed using continuous and discrete design variables for an active composite rotor blade to maximize the dynamic active twist while satisfying a series of constraints on blade cross-section parameters, stiffness, and strength. The optimization framework developed includes the Intelligent Cross-Section Generator as the cross-section and mesh generator, University of Michigan/Variational Asymptotic Beam Sectional analysis code for active cross-sectional analysis, and Rotorcraft Comprehensive Analysis Software for aeroelastic analysis of the active twist rotor blade. The optimization problem is solved using a surrogate-based approach in combination with the Efficient Global Optimization algorithm. In this paper, the results with mixed design variables are obtained with three different techniques and are compared with the results obtained using continuous design variables.
\end{abstract}

\section{Nomenclature}

$C_{T} \quad=$ coefficient of thrust

$c \quad=$ blade chord, $\mathrm{m}$

$E_{i i} \quad=$ elastic modulus (where $i$ is equal to 1,2 , and 3), $\mathrm{N} / \mathrm{m}^{2}$

$F_{z 4} \quad=$ amplitude of vertical force at the hub corresponding to $4 /$ rev frequency, $\mathrm{N}$

$G_{i j} \quad=$ shear modulus, $\mathrm{N} / \mathrm{m}^{2}$

$M_{X} \quad=$ rolling moment at the hub in fixed frame, $\mathrm{N} \cdot \mathrm{m}$

$M_{Y} \quad=$ pitching moment at the hub in fixed frame, $\mathrm{N} \cdot \mathrm{m}$

$M_{11} \quad=$ mass per unit length, $\mathrm{kg} / \mathrm{m}$

$R=$ blade radius, $\mathrm{m}$

$S_{44} \quad=$ cross-sectional torsional stiffness, $\mathrm{N} \cdot \mathrm{m}^{2}$

$\varepsilon_{i j} \quad=$ cross-sectional strains

$\theta_{i / \text { rev }}=$ amplitude of dynamic twist corresponding to $i /$ rev frequency (where $i$ is equal to 3,4 , and 5), deg

$\theta_{i / \text { rev,max }}=$ maximum amplitude of dynamic twist obtained from optimization at $i / \mathrm{rev}$ actuation frequency (where $i$ is equal to 3,4 , and 5), deg

$\theta_{\text {stat }} \quad=$ static twist per unit length, deg $/ \mathrm{m}$

$\theta_{345 / \mathrm{rev}}=$ nondimensionalized amplitude of dynamic twist corresponding to 3,4 , and $5 / \mathrm{rev}$ frequencies

$\mu$

$=$

\section{Introduction}

$\mathbf{H}$ IGH vibratory loads observed during forward-flight conditions have been one of the primary concerns that have limited the use of helicopters in spite of their superior landing and takeoff capabilities. A brief description of all the approaches and the current state of art for vibration reduction in helicopters is described in [1- $\underline{3}]$. Among the various active control methodologies that have shown potential, the integral twist actuation is one of the promising techniques for vibration reduction without the use of hydraulic power and moving parts in the rotating system. By individually controlling the

Presented as Paper 2013-1774 at the 54th AIAA/ASME/ASCE/AHS/ASC Structures, Structural Dynamics, and Materials Conference, Boston, MA, 811 April 2013; received 28 October 2013; revision received 27 January 2014; accepted for publication 7 March 2014; published online 16 June 2014. Copyright $\odot 2014$ by Devesh Kumar and Carlos E. S. Cesnik. Published by the American Institute of Aeronautics and Astronautics, Inc., with permission. Copies of this paper may be made for personal or internal use, on condition that the copier pay the $\$ 10.00$ per-copy fee to the Copyright Clearance Center, Inc., 222 Rosewood Drive, Danvers, MA 01923; include the code 1533-385X/ 14 and $\$ 10.00$ in correspondence with the CCC.

*Graduate Research Student, Department of Aerospace Engineering. Member AIAA.

${ }^{\dagger}$ Professor, Department of Aerospace Engineering. Fellow AIAA. twist of each blade, the local aerodynamics can be altered to obtain favorable vibration and noise reduction, and possible improvement in the performance of the rotor blade. The twist actuation can be obtained by embedding active fiber composites (AFCs) or macrofiber composites $[4,5]$ in the blade along its span to twist it. But, regardless of the technique, there is the need to optimize the material distribution along the blade in order to maximize the twist actuation. The fact that the actuators are also part of the primary blade structure (e.g., changing active ply orientation changes actuation authority and, concomitantly, alters the blade stiffness properties) makes it much more difficult to reach that optimum design. Different attempts have been made to design active twist rotors. The most recent reviews of the different developments associated with the active twist rotor concepts are provided in $[2, \underline{3}, 6]$. In this paper, only the studies relevant to the design and optimization of active twist rotors are discussed.

The blade designs of the active twist rotor used in the NASA/U.S. Army/Massachusetts Institute of Technology (MIT) Active Twist Rotor (ATR) program [7] and in the Defense Advanced Research Projects Administration/Boeing Company/MIT program [5] were accomplished through the exploration of several design candidates based on existing passive blades. Among the various candidates, the one with the largest static twist actuation was selected as the final design. No multidisciplinary optimization was used for those designs. The first attempt to introduce mathematical optimization for designing active twist rotor came from Cesnik et al. [조의 and Mok [10]. Their optimization framework focused on designing the crosssectional layouts along the span that maximize the static twist actuation while satisfying the constraints on the chordwise location of cross-sectional center of gravity (CG) and shear center (SC), the blade mass per unit length, torsional frequency, and the maximum strain throughout the laminates. The design variables used in the analysis were composite ply thickness and angle, chordwise location of the spar web, and ballast mass and its chordwise location. The framework included the University of Michigan/Variational Asymptotic Beam Sectional analysis (UM/VABS) [11] for active crosssectional analysis, DYMORE [12] for the geometrically exact beam analysis, a cross-sectional parametric mesh generator, and MATLAB®'s gradient-based optimizer fmincon. Among the results, it was shown that the ATR blade [4] could be redesigned to exhibit at least a $30 \%$ higher actuation authority when compared to the original design. Furthermore, [10] demonstrated that a highauthority advanced ATR concept could be achieved for an Apacheinspired rotor using the same optimization framework. More recently, Thornburgh et al. [13] performed parametric studies on model-scale blades in order to determine the variables critical for static active twist response using an updated version of the optimization framework of [ $\underline{8}-10]$. The effects of cross-sectional constraints like mass per unit length, chordwise location of SC and CG, natural frequencies of the 
blade, and the material stresses on twist rate were also investigated. They further looked at the design of an active cross section for a fullscale rotor and compared the cross-sectional differences between model-scale and full-scale blade designs that are necessary to achieve the maximum twist response during operation. In the Friendcopter program [14], the elastic and piezo-induced effects were determined based on three-dimensional ANSYS finite element modeling of a blade section. In that study, the objective was to maximize the twist per unit span of a uniform beam section under given constraints on airfoil shape, chordwise location of CG and SC, torsional frequency, and beam stiffness. The design variables used were chordwise location, length, and thickness of piezoelectric layer; ballast mass; and four geometric parameters that define the front $C$ spar. A similar framework was used with the response surface technique for optimization in [15-17]. Approximations of the original functions for constraints and objective function were obtained using low-order polynomials. In [17], the active twisting moment produced by piezoelectric actuators was maximized.

Sekula et al. [18,19] and Wilbur and Sekula [20] conducted a series of parametric design studies with structural and aerodynamic parameters to understand their effect on twist actuation in dynamic conditions. In the parametric study with structural variables [19], the effects on blade active twist, required rotor power, blade loads, and vibratory hub loads were characterized due to the variation in blade torsional, flapwise, and lead-lag stiffness; sectional mass and torsional inertia; and chordwise location of CG and SC. Analyses were conducted using CAMARAD II, and in those studies, the effect of the embedded actuators was represented by torsional moments at the blade root and at the blade tip, so as to produce equal but opposing loads. In a similar study, the effects of aerodynamic parameters $[18,20]$ like linear blade twist, blade tip sweep, droop, and taper on active twist performance were determined. Based on the analysis, an advanced active twist rotor candidate design with a -10 deg linear twist distribution along the radius, a tip region with a 30 deg sweep, a 10 deg droop, and a 2.5:1 taper ratio was proposed. Although the dynamic analysis of the rotor blade was included, the external active twisting moment applied was assumed to be independent of variation in blade structural and aerodynamic properties. Also, the final proposed design was based on trend observations made during the parametric studies and did not use any mathematical optimization technique.

To achieve maximum vibration reduction, the active blades should provide the highest twist authority over a range of rotor frequencies of interest (and not necessarily for the nonrotating, static condition). For a four-bladed rotor, actuation frequencies of 3,4 , and $5 / \mathrm{rev}$ are the most effective for vibration reduction. Therefore, the optimization must aim to maximize the twist authority under a range of predetermined frequencies for the rotor dynamic operating conditions. The sizing of the blade (along with the embedded actuators) needs to be done dynamically, resulting in an optimization problem with the amplitude of dynamic twist at a range of frequencies as its objective function. This is more suitable for optimum active twist rotor blade design. Dynamic twist can be defined as the variation in blade twist obtained due to twist actuation in rotating condition.

In a previous work [21], preliminary optimization with dynamic twist as the objective function was performed with a limited number of (six) design variables, and it was demonstrated that the dynamic twist obtained from twist actuation is the true measure of control authority for vibration reduction. During the optimization process, the optimizer tries to increase the amplitude of dynamic twist by dynamically tuning the blade's first torsion frequency and by increasing the chordwise coverage of active material to increase the active twisting moment. Some of the key results from the earlier study are the following:

1) The design corresponding to maximum static twist is different from the design corresponding to maximum dynamic twist.

2) The optimization studies for maximizing dynamic twist can be performed in hover conditions for the ease of analysis. In the parametric study performed, it was observed that the dynamic twist obtained in hover condition is very close to that obtained in forwardflight conditions, for a fixed input voltage.
3) The optimum design obtained at one particular actuation frequency may not be optimum at a different actuation frequency. Hence, while designing an active twist rotor for vibration reduction, it is desirable to increase the amplitude of tip twist at a range of actuation frequencies.

Optimization approaches suitable to deal with larger number and different types of design variables are needed to fully explore the active blade design space. In addition to the design variables used in the previous study [21], the thickness and orientation of different plies used in the cross section also need to be considered as design variables. The plies used in the fabrication of composite rotor blade are made up of discrete layers, each with a prescribed thickness (prepreg composites). Therefore, discrete optimization needs to be performed in order to design a realistic rotor blade. Conventional optimization methods are not suitable for working with mixed (both real and integer) types of design variables.

For optimizing complex composite structures where timeconsuming finite element analysis is required, surrogate modeling and response surface methods are proposed that efficiently explore the design space and limit the number of finite element analysis runs. Surrogate-based optimization techniques have been used earlier for the design of the composite rotor blade $[22,23]$ and for the design of an active rotor blade with a Gurney flap in [24]. However, in these studies, only continuous design variables were considered. Guido et al. [25] presented a mixed continuous-discrete variable optimization for the design of composite panel using surrogate modeling. Here first, a solution with continuous design variables is determined and the solution with a mixed design variable is obtained by branching into subproblems.

For this paper, mixed-variable optimization is performed in three different ways inside a surrogate based optimization framework; namely, 1) direct mixed-variable optimization, 2) constrained mixedvariable optimization, and 3) sequential constrained gradient-based optimization. Results obtained from these three optimization techniques are compared with those obtained using continuous variable optimization. In this paper, the optimization with continuous design variables is performed using a combination of non-gradient-based optimization [genetic algorithm (GA)] and gradient-based optimization, as described in [26,27]. (GA is used to obtain the starting points for gradient-based optimization.)

\section{Optimization Framework}

In the optimization problem considered here, the ply thicknesses and ply angles are treated as discrete design variables, whereas the ballast masses, the chordwise location of vertical spar web, and the chordwise location where the spar plies end are treated as continuous design variables. The ply thickness is an integer multiple of the nominal prepreg ply thickness, and it is referred to as "normalized ply thickness" in rest of the paper. The basic mixed-variable optimization problem is solved using the genetic algorithm in MATLAB 2012's Global Optimization Toolbox. It is based on special creation, crossover, and mutation functions that enforce the variables to be integers, as described in [28]. The genetic optimization process is then combined with the gradient-based optimization to obtain an optimum design with continuous and mixed design variables in an efficient manner.

The architecture of the framework used to obtain solution for a mixed-variable optimization problem is shown in Fig. 1. All the components of the mixed-variable optimization framework are summarized in the following section. Detailed descriptions of the framework are available in [3,29].

In the aeroelastic (ModelCenter) analysis, the complete aeroelastic analysis of the rotor blades with active twist is performed. The analysis process described in Fig. 2 is a modified version of the work presented in $[21,29]$, but it is now accounting for the presence of active materials embedded in the blades. It consists of three main components, namely, the Intelligent Cross-Section Generator (IXGEN), UM/VABS, and the Rotorcraft Comprehensive Analysis Software (RCAS). 


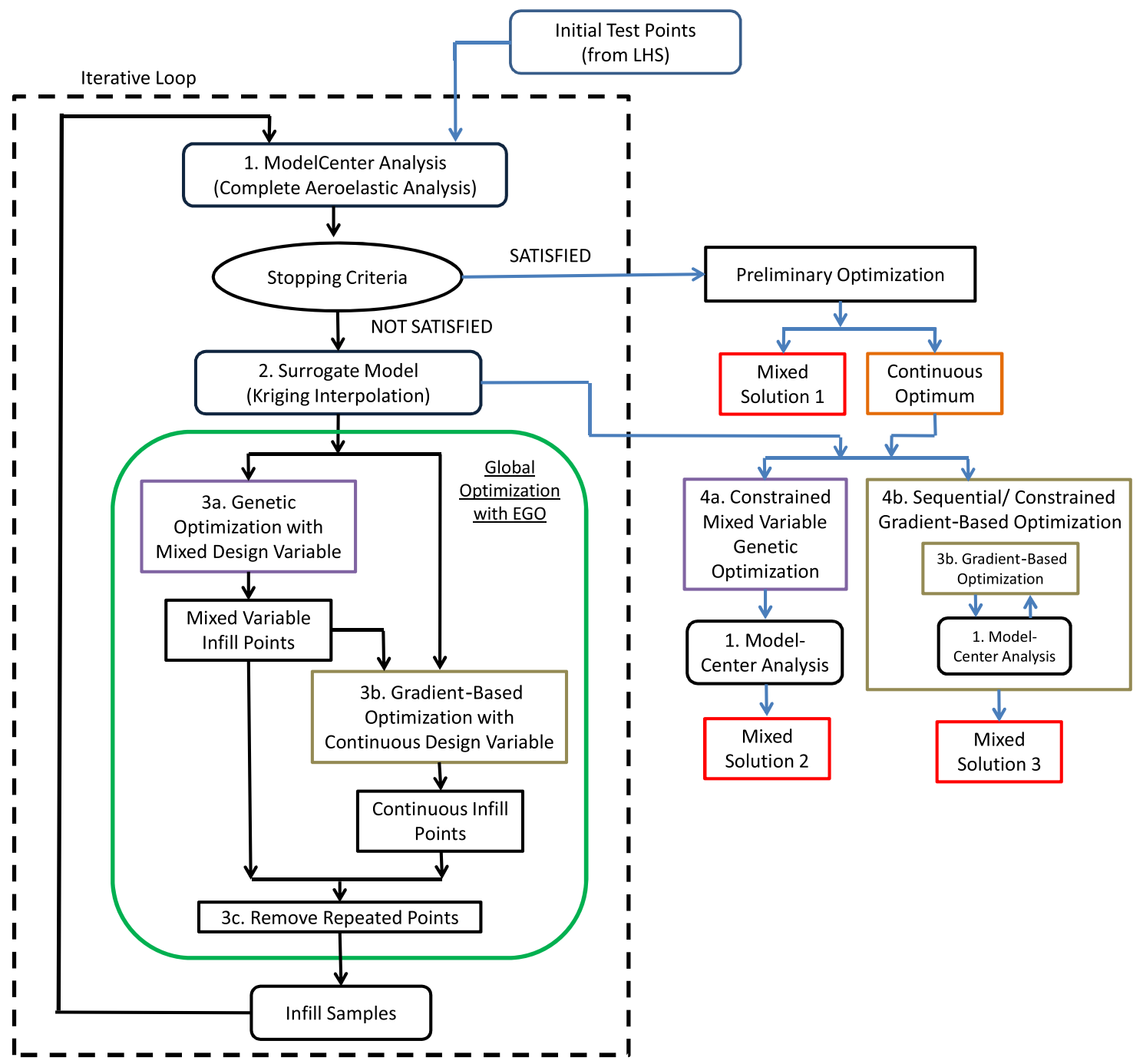

Fig. 1 Augmented optimization framework for continuous/discrete design variables.

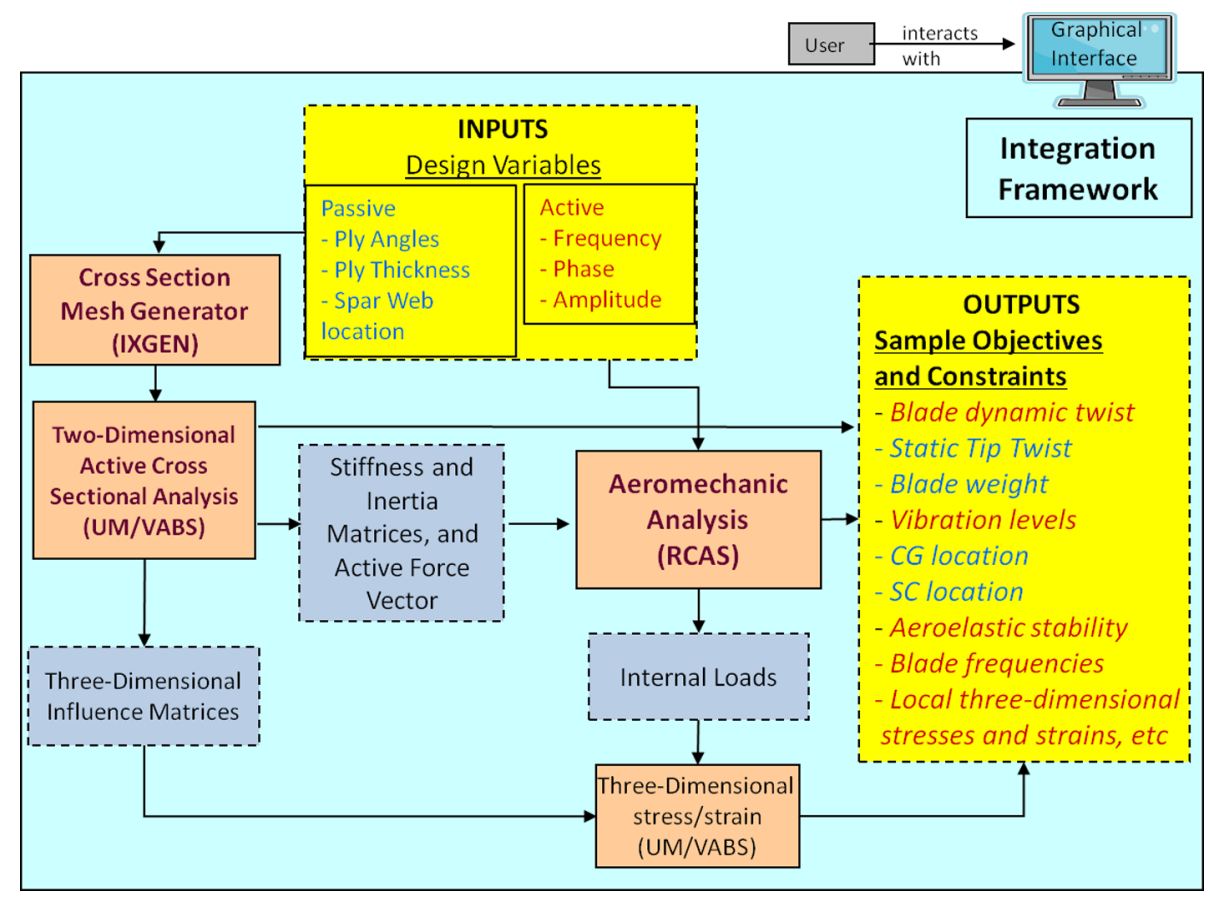

Fig. 2 Aeroelastic analysis environment for active twist rotors (inside ModelCenter). 
The Intelligent Cross-Section Generator [30] is a rotor blade modeling environment that allows the user to quickly and easily define a rotor blade as a sequence of cross sections stacked in the spanwise direction along a user-defined stacking axis. Based on the cross-sectional design parameters specified by the user or the optimizer, IXGEN generates the finite element mesh for UM/VABS. In UM/VANS analysis code, coupled equations of electrothermoelasticity in the cross section are solved through an asymptotic approximation [11]. UM/VABS provides cross-sectional stiffness, inertia, and actuation forces/moments to be used in blade (beam) analysis. It also calculates cross-sectional center of gravity and shear center. The Rotorcraft Comprehensive Analysis System [31] is a comprehensive multidisciplinary computer software system for predicting the performance, control, aeroelastic stability, loads, vibration, and aerodynamic characteristics of rotorcraft. For the RCAS analysis, structural properties of the rotor blades are provided by UM/ VABS. The magnitude of the active twisting moment determined using $\mathrm{UM} / \mathrm{VABS}$ is used as the amplitude of the external twisting moment applied to nodes of the blade in the RCAS beam model. The frequency and phase of the twisting moment are provided by the user or the optimizer. In turn, RCAS evaluates the blade dynamic twist response for the prescribed frequency range, which will be used as the objective function. Finally, all these solvers are wrapped in ModelCenter [32]. Any parameter used by IXGEN in the geometry parameterization can be used as a design variable for optimization or parametric studies. Any response parameter produced by either UM/VABS or RCAS that is exposed by this environment is available to the next level (optimizer) as either a constraint or objective function. To reduce the computational time for the aeroelastic analysis in RCAS, the "periodic analysis" is performed instead of using the "trim analysis" (discussed in more detail in the following section). All the aeroelastic simulations performed using RCAS for the optimization studies are done in hover condition. It was shown in [3] that the trends obtained in hover hold in forward flight.

The stopping criteria can either be based on the maximum number of iterations allowed or on the difference between the optimal value of the objective function obtained from successive iterations. In the analysis performed here, the optimization process was stopped after four to six iterations. It was observed during the optimization that the difference between successive optimal points reduced and the accuracy of the surrogate models improved with each iteration.

In order to form the surrogate, the objective function must first be evaluated over an initial set of design points. The surrogate is then generated by interpolating the initial design points. The MATLAB Latin hypercube sampling (LHS) function lhsdesign was used to generate the space-filling design of experiments used in this study. The points in the Latin hypercube represent the design points at which aeroelastic simulations are to be conducted. Each simulation is independent of the simulations at other design points; therefore, the initial set of sample points can be generated using distributed computers. Once an initial set of fitting points have been produced, kriging interpolation $[33,34]$ is used to create the surrogate for the objective function and constraints. After the surrogate models are created using kriging, the efficient global optimization (EGO) algorithm [35] is used to determine optimum points. The EGO algorithm accounts for uncertainty in the surrogate prediction, and it is very efficient in exploring the complete design space. More details related to the surrogate-based optimization process used in this paper are presented in $[\underline{3}, \underline{21}, \underline{26}]$.

The global optimization with EGO algorithm was performed in multiple steps to account for the mixed design variables and to reduce the computational time. In the first step, genetic optimization is performed with mixed design variables, where some of the design variables are continuous, whereas the remaining ones are discrete. It was observed that the genetic algorithm works faster when some of the variables are treated as discrete instead of the case when all the design variables are continuous. Hence, genetic optimization was used to obtain optimum results with mixed design variables only. The results obtained from this analysis are referred to as "mixed-variable infill points." It should be noted that multiple points (a set of best 5-10 points) are selected at the end of each optimization, and not just the one optimum point. These multiple points represent different local minima in the design space and form a part of the infill samples for the next round of iteration. The mixed-variable infill points are also used as the starting points for the gradient-based optimization performed on the surrogate models. The gradient-based optimizer provides a set of continuous optimum points. The gradient-based optimization is performed using the fmincon function in MATLAB. The set of points obtained at the end of the continuous optimization are referred as "continuous infill points."

The set of best points obtained from genetic optimization and gradient-based optimization are used as infill sample points. Before transferring these points to the next stage, repeated points are removed from the analysis by checking the absolute distance between the design points.

For the iterative loop, the complete aeroelastic analysis is performed again at the infill sample points using the ModelCenter environment. The results obtained from the new points are used to update the surrogate model for all the constraints and the objective function. The process of global optimization with genetic algorithm and gradientbased optimization is performed again.

For the preliminary optimization result that is obtained at end of the iterative loop, the set of points that satisfy all the constraints are sorted in the order of increasing objective function. The best point obtained is referred as the "continuous optimum," and it represents the best design point with continuous design variables. Next, the points where the normalized ply thicknesses and ply angles have discrete values are sorted out of the group. The point with the best objective function in this group is referred to as "mixed solution 1." This point is the most optimum solution obtained at the end of the iterative loop where the discrete design variables have integer values only.

The mixed-variable solution can also be obtained in two other different ways using the continuous optimum point obtained earlier. In the first method, the genetic optimization for mixed design variable is used, whereas the second method involves the usage of a gradientbased optimizer. These two methods are summarized here.

\section{A. Constrained Mixed-Variable Genetic Optimization}

This optimization is similar to what was performed in "optimization with EGO algorithm," except that the bounds for discrete design variables are modified such that a discrete solution is determined near the continuous optimum point. For example, if the continuous optimum point gives a value of 1.36 for one of the normalized ply thickness, then a lower bound of 1 and an upper bound of 2 are used for this ply thickness in the genetic optimization. The bounds for a continuous design variable are kept unchanged during this process. The mixed-variable solution obtained at the end of this optimization process is referred to as "mixed solution 2."

\section{B. Sequential Constrained Gradient-Based Optimization}

Another approach for obtaining a mixed-variable solution using the continuous optimum design is the classical sequential optimization approach, which can be performed using a gradient-based optimizer. In this approach, if any of the discrete design variables in continuous optimum has a value close to an integer, then the value for that particular design variable is fixed to that integer value and it is not considered a design variable anymore. For example, if the value corresponding to one of the discrete design variable is 4.93 in continuous optimum, then the value for this design variable is fixed to 5 and it is not considered a design variable. In the next step, the value of one more discrete design variable is fixed to an integer value and the process is repeated till all the discrete design variables have been assigned a discrete value. The solution obtained at the end of this method is referred to as "mixed solution 3." This optimization technique has the advantage that it provides a mixed-variable solution using a gradient-based optimizer. However, the optimization needs to be performed multiples times, depending upon the number of discrete design variables in the problem. Every time, the time to convergence decreases as the size of the problem decreases, and the starting conditions are very close to the optimum. 


\section{Optimization Problem Definition}

\section{A. Baseline Rotor Blade}

The baseline rotor blade used for the optimization studies in this paper is the NASA/U.S. Army/MIT active twist rotor, as described in [21]. The ATR blade [7,36] was originally designed to study the effects of twist actuation on vibration and noise reduction, and performance improvement in helicopter rotors. The 9- $\mathrm{ft}$ diameter four-bladed rotor was tested at NASA Langley Research Center's Transonic Dynamics Tunnel and was the first-of-a-kind system to demonstrate vibration reduction using embedded active fiber composites in open- and closed-loop forward-flight conditions [37]. This particular rotor blade was chosen for this study due to its known properties and available experimental and computational results [4]. Figure 3 shows the planform view of the blade and its corresponding dimensions. The airfoil for this blade is the NACA 0012, and it is uniform along the blade radius. The reference cross-sectional layup is shown in Fig. 4, whereas Table 1 lists the ply angles for all the plies used in the cross section of the rotor blade. Among the plies used, E-Glass is bidirectional, whereas S-Glass and AFC plies are unidirectional. The specific material properties can be found in Table 2 .

The characteristic properties of the baseline ATR blade and its structural frequencies at $100 \% \mathrm{rpm}$ are listed in Tables 3 and 4 , respectively. Blade structural frequencies in vacuum were obtained using RCAS. For trim analysis (used in preliminary analysis and postprocessing), the trim targets used are $\mathrm{C}_{T}=0.0066$, there are no cyclic moments $\left(M_{x}=0\right.$ and $\left.M_{y}=0\right)$, and the blade pitch settings are used as the trim variables (wind-tunnel trim).

\section{B. Design Variables and Constraints}

In the first study, the normalized ply thicknesses of different plies used in the cross section are considered as design variables, along with the variables described in [21]. To make the rotor blade design more realistic, the location of the first ballast mass is fixed near the leading edge at $x=0.02 c$, whereas the second ballast mass is located just in front of the vertical spar web. (This is done to ensure that the ballast mass is added in the region where passive plies can be used to support it.) Due to these changes, there were small changes in the dynamic properties of the baseline case. The set of design variables and their upper and lower bounds are given in Table 5. To prevent the mesh generator from crashing, the lower bound on normalized ply
Table 1 Ply angles for the different plies in the baseline ATR cross section

\begin{tabular}{lc}
\hline \hline Ply no. & Angle, deg \\
\hline 1 & $0 / 90$ \\
2 & 45 \\
$2 \mathrm{a}$ & 0 \\
3 & \pm 45 \\
4 & -45 \\
5 & $0 / 90$ \\
6 & $0 / 90$ \\
7 & $0 / 90$ \\
\hline \hline
\end{tabular}

Table 2 Material properties

\begin{tabular}{lccc}
\hline \hline & E-Glass & S-Glass & AFC \\
\hline Thickness, $\mu \mathrm{m}$ & 114.3 & 230 & 200 \\
Density, $\mathrm{kg} / \mathrm{m}^{3}$ & 1720 & 1860 & 4060 \\
$E_{11}, \mathrm{GPa}$ & 20.7 & 43.4 & 30.2 \\
$E_{22}, \mathrm{GPa}$ & 20.7 & 12 & 14.9 \\
$E_{33}, \mathrm{GPa}$ & 20.7 & 12 & 14.9 \\
$G_{12}, \mathrm{GPa}$ & 4.1 & 3.6 & 5.13 \\
$G_{13}, \mathrm{GPa}$ & 4.1 & 3.6 & 5.13 \\
$G_{23}, \mathrm{GPa}$ & 4.1 & 3.6 & 5.13 \\
$\nu_{12}$ & 0.13 & 0.28 & 0.454 \\
$\nu_{13}$ & 0.13 & 0.28 & 0.454 \\
$\nu_{23}$ & 0.3 & 0.3 & 0.3 \\
\hline \hline
\end{tabular}

thickness is fixed at 0.1 instead of zero. A value of 0.1 for normalized ply thickness in an optimum design implies that that particular ply is not required in the cross section and should be removed in the next optimization. The constraints used in the optimization are listed in Table 6 .

Objective functions that are considered for optimization studies are listed next:

1) Maximize the static twist per unit length (maximum $\theta_{\text {stat }}$ ).

2) Maximize the amplitude of twist for $3 / \mathrm{rev}$ actuation frequency (maximum $\theta_{3 / \mathrm{rev}}$ ).

3) Maximize the amplitude of twist for $4 / \mathrm{rev}$ actuation frequency (maximum $\theta_{4 / \mathrm{rev}}$ ).

4) Maximize the amplitude of twist for $5 / \mathrm{rev}$ actuation frequency (maximum $\theta_{5 / \mathrm{rev}}$ ).

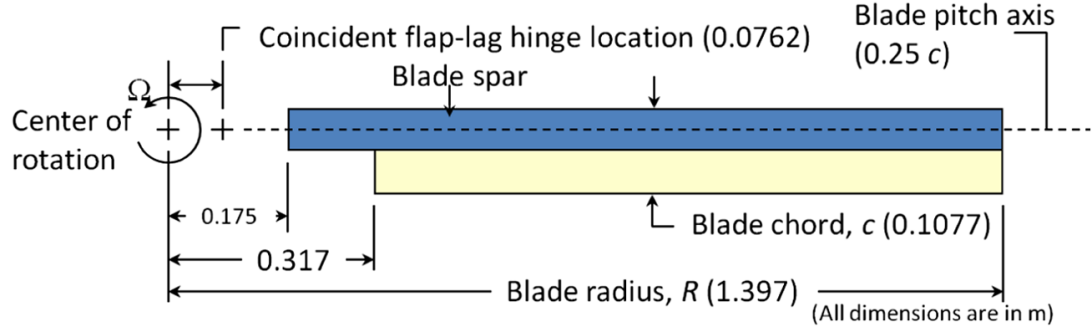

Fig. 3 Planform view of the ATR blade.

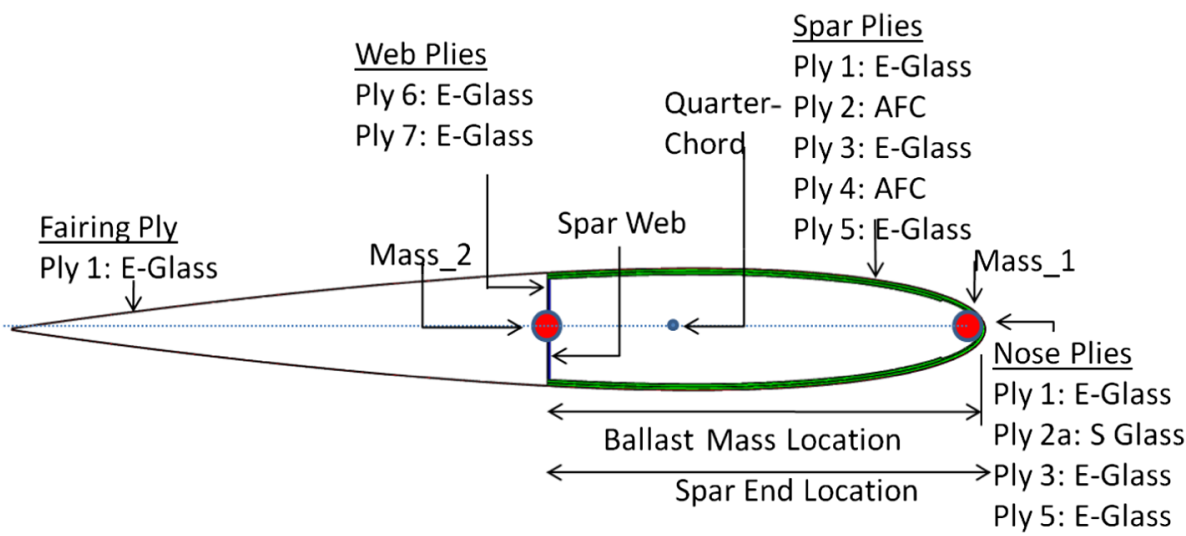

Fig. 4 Cross-sectional shape of the rotor blade (NACA 0012 airfoil). 
Table 3 Characteristics of the baseline ATR blade

\begin{tabular}{lc}
\hline \hline Parameter & Value \\
\hline Rotor type & Fully articulated \\
Number of blades & 4 \\
Blade radius $R$ & $1.397 \mathrm{~m}$ \\
Blade chord $c$ & $0.1077 \mathrm{~m}$ \\
Airfoil section & NACA 0012 \\
Blade pretwist & $-10 \mathrm{deg} / \mathrm{m}$ \\
Flap/lag hinge offset & $0.0762 \mathrm{~m}$ \\
Rotor speed & $687.5 \mathrm{rpm}$ \\
$C_{T}$ & 0.0066 \\
Air density & $2.42 \mathrm{~kg} / \mathrm{m}^{3}$ \\
\hline \hline
\end{tabular}

Table 4 Rotating natural frequencies of the baseline ATR blade

\begin{tabular}{lc}
\hline \hline Mode shape & Frequency, /rev \\
\hline First chordwise bending & 0.29 \\
First flapwise bending & 1.04 \\
Second flapwise bending & 2.78 \\
Third flapwise bending & 5.34 \\
Second chordwise bending & 5.76 \\
First torsion & 6.51 \\
\hline \hline
\end{tabular}

Table 5 Design variables and their bounds

\begin{tabular}{lccccc}
\hline \hline & Design variables & Baseline & Lower & Upper & Ply type \\
\hline 1 & Main spar location $c$ & 0.443 & 0.2 & 0.85 & \\
2 & Spar end $c$ & 0.443 & 0.2 & 0.85 & \\
3 & Ballast mass $1 m_{1}, \mathrm{~kg} / \mathrm{m}$ & 0.23 & 0 & 0.5 & \\
4 & Ballast mass $2 m_{2}, \mathrm{~kg} / \mathrm{m}$ & 0.22 & 0 & 0.5 & \\
5 & Normalized thickness of ply 1 & 1 & 0.1 & 5 & E-Glass \\
6 & Normalized thickness of ply 2a & 1 & 0.1 & 5 & S-Glass \\
7 & Normalized thickness of ply 2 & 1 & 0.1 & 5 & AFC \\
8 & Normalized thickness of ply 3 & 1 & 0.1 & 5 & E-Glass \\
9 & Normalized thickness of ply 4 & 1 & 0.1 & 5 & AFC \\
10 & Normalized thickness of ply 5 & 1 & 0.1 & 5 & E-Glass \\
11 & Normalized thickness of ply 6 & 1 & 0.1 & 5 & E-Glass \\
12 & Normalized thickness of ply 7 & 1 & 0.1 & 5 & E-Glass \\
\hline \hline
\end{tabular}

Table 6 Constraints for optimization problem

\begin{tabular}{lcc}
\hline \hline Constraints & Minimum & Maximum \\
\hline $\mathrm{SC}, \% c$ & 17 & 25 \\
$\mathrm{CG}, \% c$ & 20 & 28 \\
$M_{11}, \mathrm{~kg} / \mathrm{m}$ & 0.65 & 0.72 \\
1 st Tor Freq (/rev) & 3.0 & 7 \\
\hline \hline
\end{tabular}

5) Maximize the amplitude of twist at 3,4, and 5/rev actuation simultaneously (maximum $\theta_{345 / \mathrm{rev}}$ ). The objective function for this case is defined by

$$
\theta_{345 / \mathrm{rev}}=\frac{1}{3}\left[\frac{\theta_{3 / \mathrm{rev}}}{\theta_{3 / \mathrm{rev}, \max }}+\frac{\theta_{4 / \mathrm{rev}}}{\theta_{4 / \mathrm{rev}, \max }}+\frac{\theta_{5 / \mathrm{rev}}}{\theta_{5 / \mathrm{rev}, \max }}\right]
$$

where $\theta_{3 / \text { rev,max }}$ is the maximum amplitude of tip twist obtained from optimization at $3 / \mathrm{rev}$ actuation frequency, $\theta_{4 / \mathrm{rev} \text {,max }}$ is the maximum amplitude of tip twist obtained from optimization at $4 / \mathrm{rev}$ actuation frequency, and $\theta_{5 / \text { rev,max }}$ is the maximum amplitude of tip twist obtained from optimization at $5 / \mathrm{rev}$ actuation frequency.

\section{Periodic Analysis}

Ideally, the "trim analysis" is required in aeroelastic simulations to determine accurate blade deformations. However, the trim analysis is very time consuming and each run in RCAS takes 15-20 min for a complete aeroelastic analysis. As a result, the possibility of using "periodic analysis" for aeroelastic simulations inside RCAS was considered. In this case, the pitch settings are kept constant and a periodic solution is obtained. The rest of the analysis variables are kept the same. Thus, the blade experiences similar aerodynamic stiffness (aerodynamic forces per unit blade twist) as in the trim case, but the magnitude of aerodynamic loads is small since the initial pitch settings used are very close to zero. The computation time in RCAS (on an Intel Core 2 Quad CPU at $2.40 \mathrm{GHz}$ ) required for a periodic analysis $(\sim 1 \mathrm{~min})$ is an order of magnitude less than the computational time required for the trim analysis $(\sim 15 \mathrm{~min})$. The periodic analysis can only be used to approximate the amplitude of blade deformation due to actuation of on-blade active devices. The amplitude and mean value of tip twist for active twist actuation at 3,4, and $5 / \mathrm{rev}$ actuation frequencies for the baseline ATR blade at $\mu=0.0$ are shown in Fig. 5. As shown in Fig. 5, the amplitude of tip twist predicted by trim analysis and periodic analysis are very close to each other; however, there is a significant difference in the mean value of tip twist predicted by the two analyses. Since the amplitude of dynamic twist is used as the objective function in this paper, the periodic analysis is performed for all the aeroelastic simulations inside the optimization framework.

\section{Optimization Results}

Final results obtained for the objective functions at the end of optimization are shown in Table 7. The results show the optimum value of objective function when all the design variables are treated as continuous and when the normalized ply thicknesses are treated as discrete (obtained from all the three mixed-variable optimization techniques described in Fig. 1).

The results show that the value of objective function corresponding to optimization with continuous design variables is always better than those obtained for the cases with mixed design variables (except for the maximum $\theta_{5 / \text { rev }}$ case). In general, the results obtained from the three mixed-variable optimization techniques are close to each other. The most interesting aspect of these results is the difference between the value of the objective function when all the variables are treated as continuous and when the variables are of mixed type. The percentage difference between the value of objective function for the continuous variable case and the average value of objective function for the mixed-variable cases is shown in Table 8 . The percentage difference is less than $1.5 \%$ for maximum $\theta_{\text {stat }}$, maximum $\theta_{5 / \mathrm{rev}}$, and maximum $\theta_{345 / \mathrm{rev}}$ cases, whereas it is highest for the maximum $\theta_{3 / \mathrm{rev}}$ case.

\section{A. Optimization with Continuous Design Variables}

The value of design variables and constraints for the optimization cases with continuous design variables and for the baseline case is shown in Table 9 . As observed earlier [21], the most critical parameter for maximizing the dynamic twist is the first torsion frequency of the blade. The optimizer tries to bring the first torsion frequency of the blade closer to the actuation frequency. The chordwise location of the CG for all the cases is closer to the aft constraint limit on the CG location. This can be attributed to the increase in the value of design
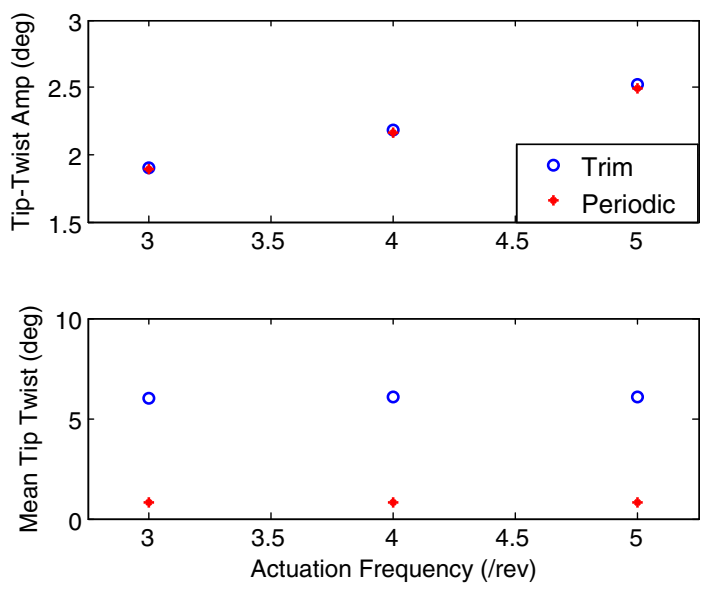

Fig. 5 Variation of mean value and amplitude (Amp) of tip twist for twist actuation at $\mu=0.0$. 
Table 7 Summary result obtained from optimization studies

\begin{tabular}{|c|c|c|c|c|c|}
\hline & Maximum $\theta_{\text {stat }}, \operatorname{deg} / \mathrm{m}$ & Maximum $\theta_{3 / \mathrm{rev}}, \mathrm{deg}$ & Maximum $\theta_{4 / \mathrm{rev}}$, deg & Maximum $\theta_{5 / \mathrm{rev}}$, deg & Maximum $\theta_{345 / \mathrm{rev}}$ \\
\hline Continuous optimum & 2.59 & 5.69 & 6.56 & 7.97 & 0.89 \\
\hline Mixed solution 1 & 2.56 & 4.24 & 5.88 & 7.79 & 0.87 \\
\hline Mixed solution 2 & 2.55 & 4.19 & 6.01 & 7.93 & 0.89 \\
\hline Mixed solution 3 & 2.55 & 4.18 & 5.85 & 7.98 & 0.89 \\
\hline Baseline & 1.34 & 1.85 & 2.06 & 2.34 & Not applicable \\
\hline
\end{tabular}

Table 8 Percentage difference between objective function for continuous variable optimization and mixed-variable optimization

\begin{tabular}{lc}
\hline \hline & Difference, $\%$ \\
\hline Maximum $\theta_{\text {stat }}$ & 1.42 \\
Maximum $\theta_{3 / \mathrm{rev}}$ & 26.13 \\
Maximum $\theta_{4 / \mathrm{rev}}$ & 9.86 \\
Maximum $\theta_{5 / \mathrm{rev}}$ & 0.88 \\
Maximum $\theta_{345 / \mathrm{rev}}$ & 1.20 \\
\hline \hline
\end{tabular}

variable "spar end," which is at its upper limit. By increasing the chordwise coverage of the active/spar plies, higher active twisting moment can be obtained, which would also result in an increase in the dynamic twist. The chordwise location of the vertical spar web is very close to the spar end value for all the optimized cases. This results in a box-type spar for all the optimized cases. The increase in the chordwise coverage of plies in the cross section leads to an increase in the torsional stiffness. For all the optimized cases (except the maximum $\theta_{3 / \text { rev }}$ case), the torsional stiffness of the optimum blade is higher than that for the baseline case, even though the first torsion frequency is lower. The placement of the first torsion frequency for the optimized cases is controlled by manipulating the values of two ballast masses. The amount of ballast mass used in the cross section is highest for the maximum $\theta_{3 / \mathrm{rev}}$ case, and it is least for the maximum $\theta_{\text {stat }}$ case. Thus, the two ballast masses play an important role in varying the first torsional frequency of the blade.

Among the ply thickness design variables, the normalized ply thickness of all passive plies (ply 1, ply 3, and ply 5) in the spar region have been reduced to their minimum allowable value. This was expected, since they do not contribute to the active twist. However, the nose ply (ply 2a) is very important for obtaining higher active twisting moment; hence, all the optimized cases show an increase in the normalized thickness of nose ply. The plies in the vertical spar web (ply 6 and ply 7) need to have sufficient stiffness in order to control the chordwise location of the shear center. Hence, even though these are passive plies, the normalized ply thickness for the spar web plies is not close to zero.

An increase in the normalized thickness of active plies is also accompanied by a corresponding increase in the torsional stiffness $S_{44}$ for the cross section. Hence, different optimized cases have different values for the normalized thickness of active plies (ply 2 and ply 4), depending upon the actuation frequency. The thickness of active plies is highest for the maximum $\theta_{\text {stat }}$ case, whereas it is the least for the maximum $\theta_{3 / \text { rev }}$ case. The results obtained for normalized ply thickness also demonstrate that, for the fixed amount of active material available, it is preferable to increase the chordwise coverage of active material as compared to increasing the thickness of active plies in order to get a higher dynamic twist amplitude. Another important trend observed is the direct correlation between torsional stiffness of the cross section and the active twisting moment generated by the embedded active plies. For all the optimized cases, the normalized thickness of the inner active ply (ply 4) is higher than that of the outer active ply (ply 2).

The performance of the optimized cases at different actuation frequencies is shown in Table 10. Each column represents one of the optimized cases, as listed in Table 9. The tip-twist values listed in Table 10 are nondimensionalized by the maximum value obtained for that objective function during the optimization study (except for $\theta_{345 / \mathrm{rev}}$ ). The results show that the value of static twist is very close to the maximum value that can be obtained for maximum $\theta_{4 / \mathrm{rev}}$, maximum $\theta_{5 / \mathrm{rev}}$, and maximum $\theta_{345 / \mathrm{rev}}$ cases. This table also highlights that the optimum solution obtained at one actuation frequency may not be optimum at a different actuation frequency; hence, the optimization needs to be performed at a range of actuation frequencies. The solution obtained by maximizing $\theta_{345 / \text { rev }}$ shows high values of dynamic twist for all the actuation frequencies considered.

Table 9 Constraints and design variables for optimization with continuous design variables

\begin{tabular}{|c|c|c|c|c|c|c|}
\hline & Baseline & Maximum $\theta_{\text {stat }}$ & Maximum $\theta_{3 / \text { rev }}$ & Maximum $\theta_{4 / \mathrm{rev}}$ & Maximum $\theta_{5 / \text { rev }}$ & Maximum $\theta_{345 / \text { rev }}$ \\
\hline \multicolumn{7}{|c|}{ Constraints } \\
\hline $\begin{array}{l}\text { First torsional frequency, /rev } \\
M_{11}, \mathrm{~kg} / \mathrm{m} \\
\mathrm{SC}, \% c \\
\mathrm{CG}, \% c\end{array}$ & $\begin{array}{l}6.53 \\
0.682 \\
18.71 \\
21.64\end{array}$ & $\begin{array}{l}5.90 \\
0.701 \\
23.50 \\
27.22\end{array}$ & $\begin{array}{c}3.71 \\
0.700 \\
17.07 \\
26.46 \\
\text { ontinuous variables }\end{array}$ & $\begin{array}{l}4.86 \\
0.719 \\
19.12 \\
27.92\end{array}$ & $\begin{array}{l}5.60 \\
0.717 \\
24.82 \\
27.41\end{array}$ & $\begin{array}{l}5.09 \\
0.719 \\
18.98 \\
27.80\end{array}$ \\
\hline $\begin{array}{l}\text { Spar end, } c \\
\text { Main web, } c \\
m_{1}, \mathrm{~kg} / \mathrm{m} \\
m_{2}, \mathrm{~kg} / \mathrm{m}\end{array}$ & $\begin{array}{c}0.443 \\
0.443 \\
0.23 \\
0.22\end{array}$ & $\begin{array}{c}0.85 \\
0.84 \\
0.299 \\
0.012\end{array}$ & $\begin{array}{l}0.818 \\
0.813 \\
0.397 \\
0.123\end{array}$ & $\begin{array}{c}0.85 \\
0.85 \\
0.346 \\
0.060\end{array}$ & $\begin{array}{l}0.842 \\
0.834 \\
0.320 \\
0.034\end{array}$ & $\begin{array}{l}0.85 \\
0.85 \\
0.334 \\
0.047\end{array}$ \\
\hline \multicolumn{7}{|c|}{ Discrete variables (normalized ply thickness) } \\
\hline $\begin{array}{l}\text { Ply } 1 \\
\text { Ply } 2 \text { a } \\
\text { Ply } 2 \\
\text { Ply } 3 \\
\text { Ply } 4 \\
\text { Ply } 5 \\
\text { Ply } 6 \\
\text { Ply } 7\end{array}$ & $\begin{array}{l}1 \\
1 \\
1 \\
1 \\
1 \\
1 \\
1 \\
1 \\
1\end{array}$ & $\begin{array}{l}0.10 \\
4.93 \\
1.16 \\
0.10 \\
1.31 \\
0.10 \\
0.59 \\
0.64\end{array}$ & $\begin{array}{l}0.16 \\
2.40 \\
0.41 \\
0.10 \\
0.68 \\
0.17 \\
0.26 \\
0.10\end{array}$ & $\begin{array}{l}0.10 \\
5.00 \\
0.84 \\
0.10 \\
1.09 \\
0.10 \\
0.43 \\
0.25\end{array}$ & $\begin{array}{l}0.11 \\
4.84 \\
1.03 \\
0.10 \\
1.27 \\
0.10 \\
0.54 \\
0.82\end{array}$ & $\begin{array}{l}0.10 \\
5.00 \\
0.98 \\
0.10 \\
1.12 \\
0.10 \\
0.59 \\
0.10\end{array}$ \\
\hline \multicolumn{7}{|c|}{ Other parameters } \\
\hline $\begin{array}{l}S_{44}, \mathrm{~N} \cdot \mathrm{m}^{2} \\
\text { Active Moment, } \mathrm{N} \cdot \mathrm{m} \\
\text { Second flap frequency, /rev } \\
\text { Third flap frequency, /rev }\end{array}$ & $\begin{array}{l}37.7 \\
0.91 \\
2.76 \\
5.26\end{array}$ & $\begin{array}{l}62.4 \\
2.83 \\
2.75 \\
5.33\end{array}$ & $\begin{array}{l}28.8 \\
1.16 \\
2.67 \\
4.80\end{array}$ & $\begin{array}{l}49.2 \\
2.21 \\
2.72 \\
5.14\end{array}$ & $\begin{array}{l}60.1 \\
2.70 \\
2.74 \\
5.26\end{array}$ & $\begin{array}{l}52.3 \\
2.37 \\
2.73 \\
5.19\end{array}$ \\
\hline
\end{tabular}


where

$$
\begin{aligned}
& \bar{\theta}_{\text {stat }}=\frac{\theta_{\text {stat }}}{\theta_{\text {stat } \text { max }}}, \quad \bar{\theta}_{3 / \mathrm{rev}}=\frac{\theta_{3 / \mathrm{rev}}}{\theta_{3 / \mathrm{rev}, \mathrm{max}}}, \\
& \bar{\theta}_{4 / \mathrm{rev}}=\frac{\theta_{4 / \mathrm{rev}}}{\theta_{4 / \mathrm{rev}, \max }}, \quad \text { and } \quad \bar{\theta}_{5 / \mathrm{rev}}=\frac{\theta_{5 / \mathrm{rev}}}{\theta_{5 / \mathrm{rev}, \max }}
\end{aligned}
$$

and

$$
\begin{aligned}
& \theta_{\text {stat,max }}=2.59, \quad \theta_{3 / \text { rev, } \text { max }}=5.69, \\
& \theta_{4 / \text { rev, } \text { max }}=6.56, \quad \text { and } \quad \theta_{5 / \text { rev, } \text { max }}=7.97
\end{aligned}
$$

\section{B. Optimization with Mixed Design Variables}

In this section, the results obtained from the optimization with continuous design variables are compared with those obtained using mixed variable for the maximum $\theta_{3 / \text { rev }}$ case (where the maximum percentage difference is observed). The comparison for other objective functions is presented in [29]. As discussed earlier, in the case of mixed design variable optimization, 4 of the 12 design variables are treated as continuous, whereas the remaining eight are discrete and can take integer values only. In this case also, the lower bound on the normalized ply thickness was fixed at 0.1 instead of zero to prevent the mesh generator from crashing.

The results obtained by maximizing $\theta_{3 / \text { rev }}$ using continuous and mixed design variables are shown in Table 11 . For this case, while the three results obtained with mixed design variables are close to each other, there is a $26 \%$ difference between the optimum values of objective function as compared to the continuous variable case. The main reason for this is the discretization of normalized thickness for the active plies. To reduce the torsional frequency (and torsional stiffness) of the blade, the normalized thickness of active plies in the cross section is well below "one" for the continuous design variable cases. But, when the normalized thickness of active plies is rounded to one for the mixed-variable case, there is a significant increase in the torsional stiffness of the cross section that could not be completely offset by adding more ballast mass. As a result, all the cases with mixed design variables show a higher torsional frequency, and thus lower amplitude for the dynamic twist.

Small differences can be observed among the three results obtained with mixed design variables. In mixed solution 1 , five plies are used in the nose region, which gives higher active twisting moment. Thus, mixed solution 1 provides the maximum dynamic twist amplitude in spite of having the highest torsional frequency. In the case of mixed solution 2, the vertical spar web is located near midchord and the first torsional frequency is closer to the actuation frequency of $3 / \mathrm{rev}$. Thus, the optimizer is trying to increase the amplitude of dynamic twist by reducing the first torsion frequency.

In this section, the optimization studies were conducted with 12 design variables, where 4 of the design variables were continuous, whereas the remaining eight were discrete. The results showed that, in some cases, it is possible to get results with mixed design variables very close to those obtained with continuous design variables, depending upon the objective function.
Table 11 Optimization Results for maximizing $\theta_{3 / \mathrm{rev}}$

\begin{tabular}{lcccc}
\hline \hline Objective function & $\begin{array}{c}\text { Continuous } \\
\text { optimum }\end{array}$ & $\begin{array}{c}\text { Mixed } \\
\text { solution 1 }\end{array}$ & $\begin{array}{c}\text { Mixed } \\
\text { solution 2 }\end{array}$ & $\begin{array}{c}\text { Mixed } \\
\text { solution 3 }\end{array}$ \\
\hline$\theta_{3 / \text { rev }, \text { deg }}$ & 5.69 & $\begin{array}{c}4.24 \\
\text { Constraints }\end{array}$ & 4.19 & 4.18 \\
\hline First torsional & 3.71 & 5.15 & 4.81 & 5.11 \\
frequency, /rev & & & & \\
$M_{11}, \mathrm{~kg} / \mathrm{m}$ & 0.700 & 0.694 & 0.683 & 0.718 \\
SC, \%c & 17.07 & 19.91 & 17.27 & 23.74 \\
CG, \%c & 26.46 & 26.93 & 27.35 & 27.61 \\
& Continuous variables & & \\
\hline Spar end, $c$ & 0.818 & 0.845 & 0.828 & 0.816 \\
Main web, $c$ & 0.813 & 0.846 & 0.599 & 0.816 \\
$m_{1}, \mathrm{~kg} / \mathrm{m}$ & 0.397 & 0.326 & 0.309 & 0.343 \\
$m_{2}, \mathrm{~kg} / \mathrm{m}$ & 0.123 & 0.046 & 0.072 & 0.068 \\
& Discrete variables & normalized ply thickness) & \\
\hline Ply 1 & 0.16 & 0.1 & 0.1 & 0.1 \\
Ply 2a & 2.40 & 5 & 2 & 4 \\
Ply 2 & 0.41 & 1 & 1 & 1 \\
Ply 3 & 0.10 & 0.1 & 0.1 & 0.1 \\
Ply 4 & 0.68 & 1 & 1 & 1 \\
Ply 5 & 0.17 & 0.1 & 0.1 & 0.1 \\
Ply 6 & 0.26 & 1 & 0.1 & 0.1 \\
Ply 7 & 0.10 & 0.1 & 1 & 1 \\
\hline \hline
\end{tabular}

Table 12 Design variables for optimization with ply thicknesses and ply angles

\begin{tabular}{lccccc}
\hline \hline & Design variables & Baseline 2 & Lower & Upper & Ply type \\
\hline 1 & Main spar location, $c$ & 0.443 & 0.2 & 0.85 & \\
2 & Spar end, $c$ & 0.443 & 0.2 & 0.85 & \\
3 & Ballast mass $1 m_{1}, \mathrm{~kg} / \mathrm{m}$ & 0.23 & 0 & 0.5 & \\
4 & Ballast Mass 2 $m_{2}, \mathrm{~kg} / \mathrm{m}$ & 0.22 & 0 & 0.5 & \\
\multicolumn{1}{c}{ Normalized ply thickness } & & \\
\hline 5 & Ply 2a thickness & 1 & 1 & 5 & S-Glass \\
6 & Ply 2 thickness & 1 & 1 & 5 & AFC \\
7 & Ply 4 thickness & 1 & 1 & 5 & AFC \\
8 & Spar web ply 6 thickness & 1 & 1 & 10 & E-Glass \\
& & Ply angles & & & \\
\hline 9 & Ply 1 angle & 0 & 0 & 90 & E-Glass \\
10 & Ply 2a angle & 0 & -90 & 90 & S-Glass \\
11 & Ply 2 angle & 45 & -90 & 90 & AFC \\
12 & Ply 4 angle & -45 & 0 & 90 & AFC \\
13 & Spar web ply 6 angle & 0 & 0 & 90 & E-Glass \\
\hline \hline
\end{tabular}

\section{Optimization Study with Ply Thicknesses and Ply Angles}

To prevent the mesh generator from crashing, the minimum allowable normalized ply thickness was fixed to 0.1 instead of using 0 for the optimization studies performed earlier. The optimization results obtained showed that the optimizer tried to reduce the normalized thickness of all passive plies in the spar region (ply 1, ply 3 , and ply 5) to 0.1 , indicating that these plies do not contribute to the dynamic twist amplitude; hence, these plies should not be included in the cross section. Therefore, in the optimization study presented in this section, ply 3 and ply 5 are removed from the analysis. Since ply 1 is the outermost ply, it cannot be removed from the cross section. Thus, the normalized thickness of ply 1 is fixed to the minimum

Table 10 Performance of optimized cases at other actuation frequencies

\begin{tabular}{lcccccc}
\hline \hline Cases & Baseline & Maximum $\theta_{\text {stat }}$ & Maximum $\theta_{3 / \mathrm{rev}}$ & Maximum $\theta_{4 / \mathrm{rev}}$ & Maximum $\theta_{5 / \mathrm{rev}}$ & Maximum $\theta_{345 / \mathrm{rev}}$ \\
\hline $\bar{\theta}_{\text {stat }}$ & 0.52 & 1 & 0.87 & 0.98 & 0.99 & 0.99 \\
$\bar{\theta}_{3 / \mathrm{rev}}$ & 0.33 & 0.68 & 1 & 0.81 & 0.69 & 0.77 \\
$\bar{\theta}_{4 / \mathrm{rev}}$ & 0.31 & 0.73 & 0.55 & 1 & 0.78 & 0.93 \\
$\bar{\theta}_{5 / \mathrm{rev}}$ & 0.29 & 0.91 & 0.16 & 0.81 & 1 & 0.97 \\
$\theta_{345 / \mathrm{rev}}$ & 0.31 & 0.77 & 0.57 & 0.87 & 0.82 & 0.89 \\
\hline \hline
\end{tabular}




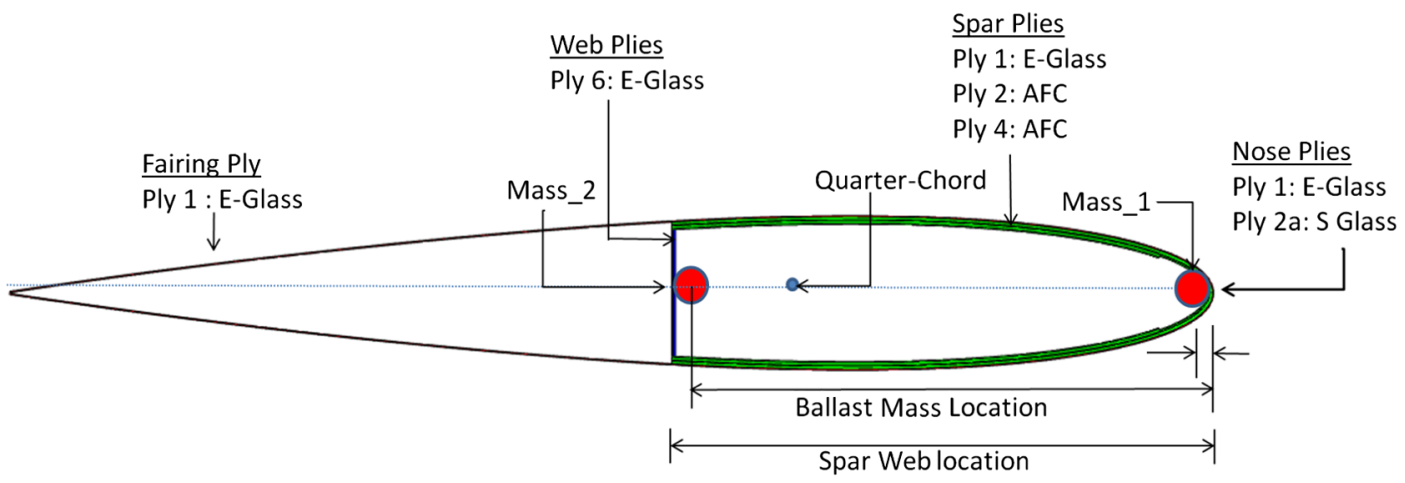

Fig. 6 Modified baseline case (baseline 2).

possible thickness, which is one. Also, in order to reduce the number of design variables, both the plies in the vertical spar web region (ply 6 and ply 7) are grouped and they are treated as one equivalent ply (ply 6) for which the thickness is a design variable. The modified cross section that is used as the baseline case is shown in Fig. 6 and is referred to as "baseline 2." The final set of design variables use in this study and their upper and lower bounds are listed in Table 12. The constraints used in this study are the same as those listed in Table 6 .

The bounds used for ply angle depend on the nature of the prepreg. For the unidirectional plies, the ply angle varies from -90 to +90 deg, whereas for the bidirectional plies, the ply angle varies from 0 to $90 \mathrm{deg}$. Even though the ply angle can be treated as a continuous design variable, it is difficult to accurately manufacture a composite structure where the ply angle has a real value. Hence, in the mixed-variable optimization performed here, the ply angles are treated as discrete design variables for the ease of manufacturing. In some of the earlier work [38], ply angles are discretized in multiples of 5 or $10 \mathrm{deg}$. The framework presented here is also capable of working with this discretization; however, for the analysis presented in this section, the ply angle is allowed to take any integer value within the bounds specified.

The final results presented here in Table 13 show only the best result obtained with mixed design variables using the design variables listed in Table 12. For all the objective functions (except maximum $\left.\theta_{5 / \mathrm{rev}}\right)$, it was observed that the final value of ply angles do not vary from their baseline values.

In all the optimized cases, the normalized thickness of active plies is equal to 1 . For the maximum $\theta_{\text {stat }}$ case, there is an increase in the thickness of nose ply only, and the chordwise coverage of active plies is at the maximum allowable value. Here, only the leading-edge ballast mass is used to get the chordwise location of the $\mathrm{CG}$ within the bounds required. Among all the optimized cases, the maximum $\theta_{\text {stat }}$ case has the highest cross-sectional stiffness.

Table 13 Results obtained for optimization with mixed design variables

\begin{tabular}{|c|c|c|c|c|c|c|}
\hline Cases & Maximum $\theta_{\text {stat }}$ & Maximum $\theta_{3 / \text { rev }}$ & Maximum $\theta_{4 / \mathrm{rev}}$ & Maximum $\theta_{5 / \mathrm{rev}}$ & Maximum $\theta_{345 / \mathrm{rev}}$ & Baseline 2 \\
\hline \multicolumn{7}{|c|}{ Objective function } \\
\hline$\left|\theta_{\text {stat }}\right|, \operatorname{deg} / \mathrm{m}$ & 2.41 & 2.22 & 2.21 & 2.39 & 2.39 & 1.67 \\
\hline$\theta_{3 / \mathrm{rev}}, \mathrm{deg}$ & 3.36 & 4.60 & 4.34 & 3.81 & 3.88 & 2.40 \\
\hline$\theta_{4 / \mathrm{rev}}, \mathrm{deg}$ & 4.30 & 5.28 & 5.41 & 5.01 & 5.31 & 2.54 \\
\hline$\theta_{5 / \mathrm{rev}}, \mathrm{deg}$ & 5.73 & 3.86 & 4.81 & 7.87 & 7.62 & 2.38 \\
\hline$\theta_{345 / \mathrm{rev}}, \mathrm{deg}$ & 0.708 & 0.769 & 0.798 & 0.867 & 0.878 & 0.408 \\
\hline \multicolumn{7}{|c|}{ Constraints } \\
\hline First torsional frequency, /rev & 5.71 & 4.71 & 4.93 & 5.48 & 5.28 & 5.48 \\
\hline$M_{11}, \mathrm{~kg} / \mathrm{m}$ & 0.694 & 0.688 & 0.697 & 0.697 & 0.720 & 0.642 \\
\hline $\mathrm{SC}, \% \mathrm{c}$ & 23.81 & 17.05 & 17.19 & 21.51 & 24.77 & 19.01 \\
\hline $\mathrm{CG}, \% c$ & 20.33 & 27.92 & 27.79 & 27.95 & 28.00 & 21.87 \\
\hline \multicolumn{7}{|c|}{ Design Variables } \\
\hline Spar end, $c$ & 0.85 & 0.849 & 0.85 & 0.839 & 0.846 & 0.443 \\
\hline Main web, $c$ & 0.85 & 0.303 & 0.318 & 0.839 & 0.843 & 0.443 \\
\hline$m_{1}, \mathrm{~kg} / \mathrm{m}$ & 0.332 & 0.271 & 0.273 & 0.313 & 0.334 & 0.23 \\
\hline$m_{2}, \mathrm{~kg} / \mathrm{m}$ & 0.009 & 0.063 & 0.060 & 0.034 & 0.038 & 0.22 \\
\hline \multicolumn{7}{|c|}{ Normalized ply thicknesses } \\
\hline Ply 2a (S-Glass) & 5 & 1 & 2 & 5 & 4 & 1 \\
\hline Ply 2 (AFC) & 1 & 1 & 1 & 1 & 1 & 1 \\
\hline Ply 4 (AFC) & 1 & 1 & 1 & 1 & 1 & 1 \\
\hline Ply 6 (E-Glass) & 1 & 9 & 10 & 1 & 1 & 1 \\
\hline \multicolumn{7}{|c|}{ Ply angles } \\
\hline Ply 1 (E-Glass) & 0 & 0 & 0 & 87 & 0 & 0 \\
\hline Ply 2a (S-Glass) & 0 & 0 & 0 & -28 & 0 & 0 \\
\hline Ply 2 (AFC) & 45 & 45 & 45 & -45 & 45 & 45 \\
\hline Ply 4 (AFC) & -45 & -45 & -45 & 45 & -45 & -45 \\
\hline Ply 6 (E-Glass) & 0 & 0 & 0 & 1 & 0 & 0 \\
\hline \multicolumn{7}{|c|}{ Other parameters } \\
\hline$S_{44}, \mathrm{~N} \cdot \mathrm{m}^{2}$ & 56.5 & 32.9 & 37.0 & 58.1 & 55.8 & 25.1 \\
\hline Active Moment, $\mathrm{N} \cdot \mathrm{m}$ & 2.38 & 1.37 & 1.54 & 2.44 & 2.33 & 0.76 \\
\hline Second flap frequency, /rev & 2.77 & 2.77 & 2.78 & 2.76 & 2.76 & 2.72 \\
\hline Third flap frequency, /rev & 5.40 & 5.42 & 5.44 & 5.35 & 5.36 & 5.07 \\
\hline Maximum $\varepsilon_{11}(\mu \varepsilon)$ & 2489 & 3994 & 3364 & 1340 & 2896 & 3935 \\
\hline Maximum $\varepsilon_{12}(\mu \varepsilon)$ & 4220 & 5600 & 4748 & 6765 & 4711 & 5591 \\
\hline
\end{tabular}


In the maximum $\theta_{3 / \text { rev }}$ case, the removal of passive plies help in obtaining better dynamic twist as compared to what was obtained in Table 11 with mixed design variables. Unlike the results obtained in Table $\underline{11}$, the vertical spar web is located near the quarter-chord due to which the chordwise location of shear center is closer to its lower limit. As compared to the maximum $\theta_{\text {stat }}$ case, the normalized thickness of the nose ply, ply $2 \mathrm{a}$, is at its minimum value, whereas the normalized thickness of vertical spar web ply, ply 6 , is near the maximum allowable value. Thus, in the maximum $\theta_{3 / \text { rev }}$ case, the optimizer is trying to lower the torsional stiffness as much as possible in order to get the first torsion frequency closer to the actuation frequency. The results obtained for maximum $\theta_{4 / \mathrm{rev}}$ and maximum $\theta_{3 / \mathrm{rev}}$ cases are very close to each other. This is specific to this problem, and it can be attributed to the bounds used for constraints and design variables in the optimization problem definition. The only noticeable difference between the maximum $\theta_{4 / \text { rev }}$ case and maximum $\theta_{3 / \text { rev }}$ case is in the thickness of nose and vertical spar web plies. In the maximum $\theta_{5 / \mathrm{rev}}$ case, changes are observed in the ply angle for nose ply only. As in the maximum $\theta_{\text {stat }}$ case, the thickness of nose ply is at its upper bound and the vertical spar web is located near the trailing edge. The result obtained for maximum $\theta_{345 / \text { rev }}$ case is close to that obtained for maximum $\theta_{5 / \mathrm{rev}}$ and maximum $\theta_{\text {stat }}$ cases. In the optimization studies presented in this section, the crosssectional strains are not included as part of the constraints. The results obtained here show that the maximum values of $\varepsilon_{11}$ and $\varepsilon_{12}$ in the cross section for all the optimized cases are approximately equal to or less than those obtained for the baseline case (which was shown experimentally to be sufficient to withstanding the loads). Thus, the blade designs obtained from these optimization studies have sufficient strength.
The shape of the cross section for the optimized cases is shown in Fig. 7. In these cross sections, the ballast masses are represented using circles, where the diameter is proportional to the mass value.

\section{Postprocessing of Optimization Results}

The final results obtained at the end of optimization process with mixed design variables, as shown in Table 13, are analyzed further in order to check their validity. Here, two different kinds of analyses are performed. In the first analysis, variation of the amplitude of dynamic twist with advance ratio is determined for different actuation frequencies. And finally, circle plots are generated for each of the optimized cases in forward-flight condition at different actuation frequencies in order to make sure that the optimized results do provide higher authority for vibration reduction at the hub.

\section{A. Effect of Advance Ratio}

In this section, aeroelastic studies with trim analysis were performed for each of the optimized cases at different forward-flight speeds. This study was performed to verify the original assumption that there is no significant change in the amplitude of tip twist with forward-flight speed. The results obtained for actuation frequencies of 3, 4, and 5/rev are shown in Figs. 8 , 9, and 10, respectively. The results obtained show that the variation in the amplitude of dynamic tip twist with advance ratio is small. Since the results presented here include trim analysis, they do not match exactly the results shown in Table 13, where periodic analysis is used. For each of the actuation frequency, the corresponding case provides maximum dynamic twist at all the advance ratios considered.
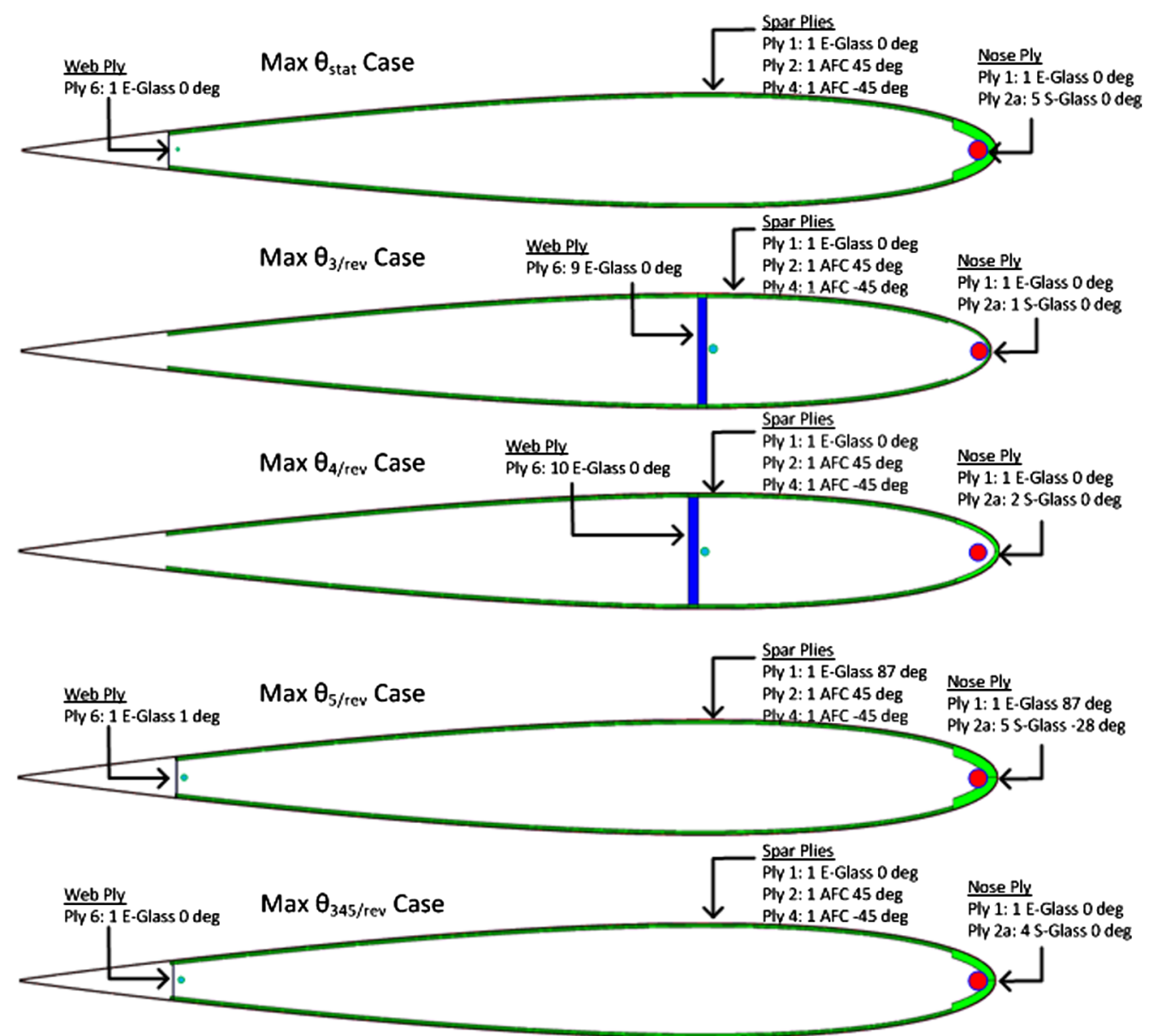

Fig. 7 Cross section for the optimized cases obtained with mixed design variables. 


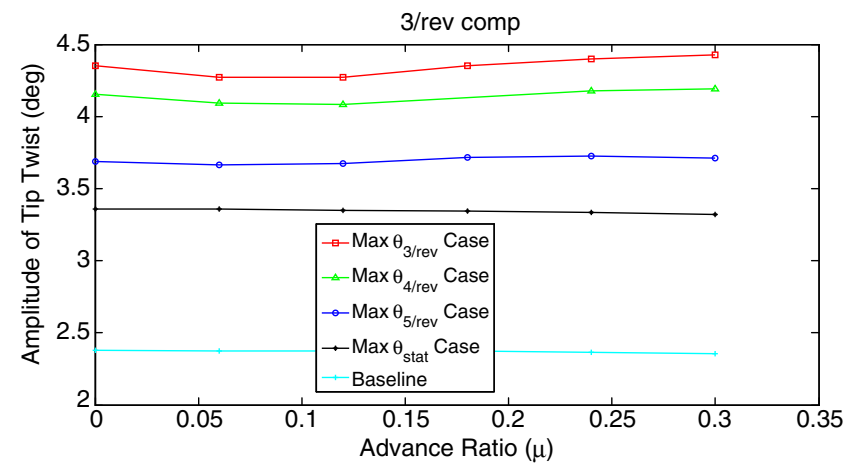

Fig. 8 Effect of advance ratio at $3 /$ rev actuation frequency.

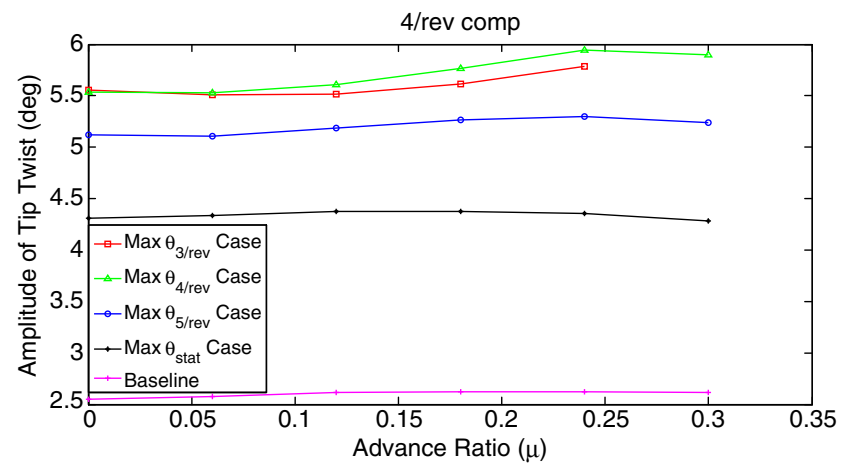

Fig. 9 Effect of advance ratio at $4 / \mathrm{rev}$ actuation frequency.

\section{B. Circle Plot for Optimized Cases}

To generate the circle plot for each of the optimized cases and the baseline case, the twist actuation is provided at a fixed frequency and the phase of actuation is varied from 0 to $360 \mathrm{deg}$ in the intervals of $30 \mathrm{deg}$. Once the response for each of the hub loads in the fixed system is obtained, Fast Fourier Transform is used to determine the sine and cosine component of the response corresponding to $4 / \mathrm{rev}$ frequency. The circle plots generated for $\mu=0.24$ and 3, 4, and 5/rev actuation frequencies for vertical components of the force at the hub $\left(F_{z}\right)$ are shown in Figs. 11, 12, and 13, respectively.

Since the optimum result obtained for the maximum $\theta_{3 / \text { rev }}$ and maximum $\theta_{4 / \text { rev }}$ cases are close to each other, the circle plots corresponding to these cases for 3 and 4/rev actuation frequencies are close to each other. As shown in Figs. 11 and 12, the circle plot corresponding to the maximum $\theta_{5 / \text { rev }}$ case has a larger size than that corresponding to the maximum $\theta_{\text {stat }}$ case. Thus, each of the dynamically optimized cases performs better than the statically optimized case for 3 and $4 / \mathrm{rev}$ actuation frequencies. In the case of a circle plot generated at a $5 / \mathrm{rev}$ actuation frequency, the maximum $\theta_{5 / \text { rev }}$ case provides the highest authority for vibration reduction, as shown in Fig. 13. Since the optimum design for the maximum $\theta_{\text {stat }}$ case is close to that for the maximum $\theta_{5 / \mathrm{rev}}$ case, the maximum $\theta_{\text {stat }}$

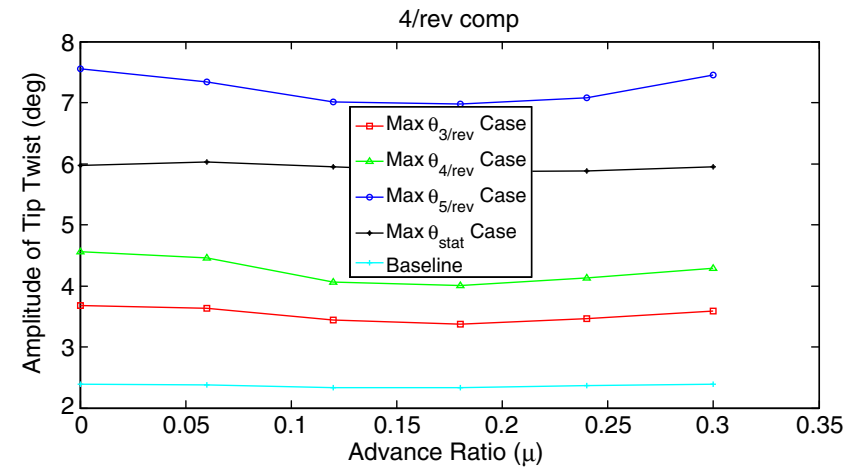

Fig. 10 Effect of advance ratio at $5 / \mathrm{rev}$ actuation frequency.

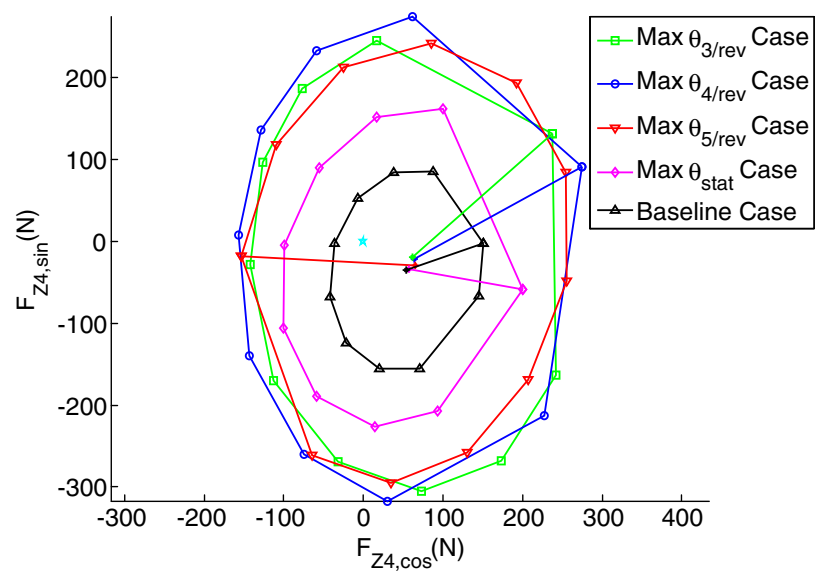

Fig. 11 Circle plot for $3 /$ rev actuation frequency.

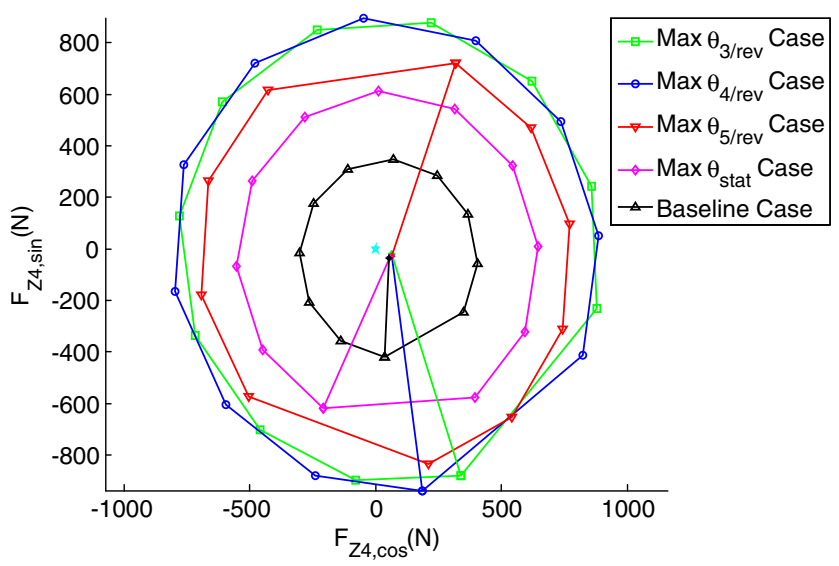

Fig. 12 circle plot for $4 / \mathrm{rev}$ actuation frequency.

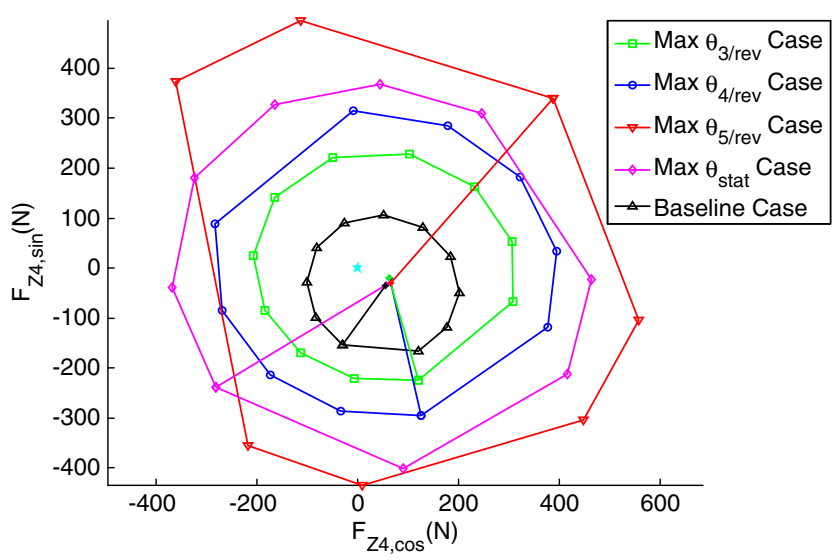

Fig. 13 Circle plot for $5 /$ rev actuation frequency.

case outperforms the maximum $\theta_{3 / \mathrm{rev}}$ and maximum $\theta_{4 / \mathrm{rev}}$ cases for vibration reduction at a $5 / \mathrm{rev}$ actuation frequency.

The results presented in this section highlight the original assumption that the authority of an active twist rotor to reduce vibratory loads at the hub can be increased by maximizing the amplitude of dynamic twist obtained from twist actuation.

\section{Conclusions}

The use of prepreg material for manufacturing composite aerospace structures leads to discrete design variables in the design and optimization studies. To obtain a realistic and manufacturable design at the end of optimization, the ply thicknesses and ply angles should be treated as discrete design variables. This paper presented 
the architecture of a design framework that can be used to perform optimization studies with mixed design variables for designing a composite active twist rotor blade. In the proposed framework, the optimum solution with mixed design variables is obtained using three different methods, in addition to the optimum design when all the variables are treated as continuous. This facilitates the designer to estimate the loss due to discretization and make necessary changes to improve the design.

The mixed design variable optimization framework was successfully used to design the cross section of a composite rotor blade with embedded active material. In the first case, ply thicknesses were considered as discrete design variables, in addition to the continuous design variables like the chordwise location of vertical spar web, ballast masses, and chordwise location where the active plies end. Here, the minimum allowable normalized thickness of prepreg plies was fixed at 0.1 instead of 0 to prevent the finite element mesh generator from crashing. The results obtained from these studies showed that some of the plies had normalized ply thickness as 0.1 in the optimum results, indicating that these plies should be removed from the analysis. In the next step, these passive plies were removed from the cross section (except the outermost ply for which the normalized thickness was fixed to 1) and the minimum allowable normalized thickness was modified to 1 . In this case, the ply angles for remaining plies were also considered as design variables.

The final results obtained showed the following:

1) The optimization studies for maximizing the amplitude of dynamic twist can be performed in hover condition (instead of multiple advance ratios) using periodic analysis (instead of full trim analysis) within a design cycle in order to reduce the computation time.

2) The difference between the results obtained from continuous and mixed-variable optimization depends on the objective function being considered.

3) The mixed design variable results obtained using three different approaches produced similar results (mixed solution 1 and mixed solution 2 are the preferred methods).

4) While maximizing the static and dynamic twist, the optimum design obtained always led to a stiffer cross section; thus, most of the optimum designs had lower cross-sectional strains (except for the 3/ rev actuation frequency case).

5) A thick prepreg layer is required near the leading edge (ply 2a) to obtain a higher active twisting moment, but it may increase the torsional stiffness, which may cause the dynamic twist performance to deteriorate.

6) For a fixed amount of active material available, the results obtained showed that increasing the chordwise coverage of active plies leads to higher static and dynamic twist as compared to increasing the thickness of active plies. Also, a box-shaped spar design, in which the chordwise location where the spar plies end and the chordwise location of the vertical spar web are close to each other, is suitable for maximizing the dynamic twist amplitude.

7) There is a significant difference in the optimum design obtained for different actuation frequencies.

8) For the results obtained in this paper, the optimum design obtained by maximizing amplitude of dynamic twist at 3,4 , and $5 / \mathrm{rev}$ actuation frequencies tends to be closer to the result obtained for maximizing the amplitude for the $5 / \mathrm{rev}$ actuation frequency. This can be attributed to the higher cross-sectional stiffness in the maximum $\theta_{5 / \text { rev }}$ case, which in turn results in higher active twisting moment.

\section{Acknowledgments}

This work was sponsored by the U.S. Army Research, Development, and Engineering Command; and the Aviation Applied Technology Directorate through Small Business Innovation Research Phase II contract number W911W6-10-C-0030. The authors would like to thank Peter Röhl (Advatech Pacific, Inc.) for providing the Intelligent Cross-Section Generator and for implementing the aeroelastic analysis environment in ModelCenter.

\section{References}

[1] Kessler, C., "Active Rotor Control for Helicopters: Motivation and Survey on Higher Harmonic Control," CEAS Aeronautical Journal, Vol. 1, Nos. 1-4, 2011, pp. 3-22. doi: $10.1007 / \mathrm{s} 13272-011-0005-9$

[2] Kessler, C., "Active Rotor Control for Helicopters: Individual Blade Control and Swashplateless Rotor Designs," CEAS Aeronautical Journal, Vol. 1, Nos. 1-4, 2011, pp. 23-54. doi:10.1007/s13272-011-0001-0

[3] Kumar, D., "Design and Analysis of Composite Rotor Blades for Active/ Passive Vibration Reduction,” Ph.D. Dissertation, Dept. of Aerospace Engineering, Univ. of Michigan, Ann Arbor, MI, 2013.

[4] Shin, S., Cesnik, C. E. S., Wilkie, W. K., and Wilbur, M. L., "Design and Manufacturing of a Model-Scale Active Twist Rotor Prototype Blade," Journal of Intelligent Material Systems and Structures, Vol. 19, No. 12, 2008, pp. 1443-1456.

doi:10.1177/1045389X07088051

[5] Rodgers, J. P., Hagood, N. W., and Weems, D., "Design and Manufacture of an Integral Twist-Actuated Rotor Blade," 38th AIAA/ ASME/ASCE/AHS/ASC Structures, Structural Dynamics, and Materials Conference, AIAA Paper 1997-1264, April 1997.

[6] Thakkar, D., and Ganguli, R., "Active Twist Control of Smart Helicopter Rotor-A Survey," Journal of Aerospace Sciences and Technologies, Vol. 57, No. 4, 2005, pp. 1-20.

[7] Cesnik, C. E. S., Shin, S., Wilkie, W. K., Wilbur, M. L., and Mirick, P. H., "Modeling, Design and Testing of the NASA/ARMY/MIT Active Twist Rotor Prototype Blade," American Helicopter Society 55th Annual Forum, American Helicopter Society, Montreal, Canada, May 1999.

[8] Cesnik, C. E. S., Mok, J., Parekh, A., and Shin, S., "Optimization Design Framework for Integrally Twisted Helicopter Blades," 45th AIAA/ASME/ASCE/ASC Structures, Structural Dynamics and Materials Conference, AIAA Paper 2004-1761, April 2004.

[9] Cesnik, C. E. S., Mok, J., Morillo, J. A., and Parikh, A. S., "Design Optimization of Active Twist Rotor Blades," 30th European Rotorcraft Forum, Royal Aeronautical Society, Marseilles, France, 2005.

[10] Mok, J., "Design Optimization for Active Twist Rotor Blades," Ph.D, Dissertation, Dept. of Aerospace Engineering, Univ. of Michigan, Ann Arbor, MI, 2010.

[11] Palacios, R., and Cesnik, C. E. S., "Cross-Sectional Analysis of Nonhomogeneous Anisotropic Active Slender Structures," AIAA Journal, Vol. 43, No. 12, 2005, pp. 2624-2638. doi:10.2514/1.12451

[12] Bauchau, O., DYMO RE User's Manual, Georgia Inst. of Technology, Atlanta, 2007.

[13] Thornburgh, R. P., Kreshock, A. R., and Wilbur, M. L., "Structural Optimization of Active-Twist Rotor Blades," American Helicopter Society, 67th Annual Forum, American Helicopter Society, Virginia Beach, VA, May 2011.

[14] Masarati, P., Morandini, M., Riemenschneider, J., Wierach, P., Gluhih, S., and Barkanov, E., "Optimal design of an Active Twist 1:2.5 Scale Rotor Blade," European Rotorcraft Forum, Royal Aeronautical Society, Florence, Italy, Sept. 2005.

[15] Kovalos, A., Barakanov, E., and Gluhihs, S., "Active Twist Model Rotor Blades with D-Spar Design,” Transport, Vol. 22, No. 1, 2007, pp. $38-44$. doi:10.1080/16484142.2007.9638094

[16] Barakanov, E., Gluhih, S., and Kovalev, A., "Optimal Design of the Active Twist for Helicopter Rotor Blades with C-Spar," Mechanics of Advanced Materials and Structures, Vol. 15, Nos. 3-4, 2008, pp. 325-334. doi:10.1080/15376490801907855

[17] Opitz, S., Riemenschneider, J., and Wierach, P., "Multidisciplinary Optimization of Adaptive Systems," Adaptronic Congress, Adaptronic Congress Veranstaltungs GbR, Berlin, May 2008.

[18] Sekula, M. K., Wilbur, M. L., and Yeager, W. T., "Aerodynamic Design Study of an Advanced Active Twist Rotor," American Helicopter Society 4th Decennial Specialist Conference on Aeromechanics, American Helicopter Society, San Francisco, CA, Jan. 2004.

[19] Sekula, M. K., Wilbur, M. L., and Yeager, W. T., "A Parametric Study of the Structural Design of an Advanced Active Twist Rotor," American Helicopter Society 61st Annual Forum, American Helicopter Society, Grapevine, TX, June 2005.

[20] Wilbur, M. L., and Sekula, M. K., "The Effect of Tip Geometry on Active-Twist Rotor Response," American Helicopter Society 61st Annual Forum, American Helicopter Society, Grapevine, TX, June 2005.

[21] Kumar, D., Cesnik, C. E. S., Rohl, P. J., and Sutton, M., "Optimization Framework for the Dynamic Analysis and Design of Active Twist 
Rotors," 68th American Helicopter Society International Annual Forum, American Helicopter Society, Fort Worth, TX, May 2012.

[22] Murugan, S., Ganguli, R., and Harursampath, D., "Surrogate Based Design Optimization of Composite Airfoil Cross Section for Helicopter Vibration Reduction," Aeronautical Journal, Vol. 116, No. 1181, 2012, pp. 709-725.

[23] Glaz, B., Friedmann, P. P., Liu, L., Kumar, D., and Cesnik, C. E. S., "The AVINOR Aeroelastic Simulation Code and its Application to Reduced Vibration Composite Rotor Blade Design," 50th AIAA/ASME/ASCE/ AHS/ASC Structures. Structural Dynamics, and Materials Conference, AIAA Paper 2009-2601, May 2009.

[24] Paternoster, A., Loendersloot, R., Boer, A. D., and Akkerman, R., "Geometrical Optimization of a Hingeless Deployment System for an Active Rotor Blade," Journal of Intelligent Material Systems and Structures, Vol. 24, No. 7, 2013, pp. 855-861. doi: $10.1177 / 1045389 X 12461720$

[25] Guido, S. D., Geijselaers, H. J. M., and Boer, A. D., "ContinuousDiscrete Variable Optimization on Composite Using Kriging Surrogate Model," 16th International Conference on Composite Structures, Faculty of Engineering of the University of Porto (FEUP), Porto, Portugal, June 2011.

[26] Kumar, D., Glaz, B., Mok, J., Friedmann, P. P., and Cesnik, C. E. S., "Determination of Optimum Camber Distribution in Rotating Wings with Deformable Airfoils for Vibration Reduction and Performance Enhancement Using Surrogate Modeling," Proceedings of European Rotorcraft Forum, Royal Aeronautical Society, Paris, Sept. 2010.

[27] Gudla, P. K., and Ganguli, R., "An Automated Hybrid GeneticConjugate Gradient Algorithm for Multimodal Optimization Problems," Applied Mathematics and Computation, Vol. 167, No. 2, 2005 , pp. 1457-1474. doi:10.1016/j.amc.2004.08.026

[28] Deep, K., Singh, K. P., Kansal, M. L., and Mohan, C., "A Real Coded Genetic Algorithm for Solving Integer and Mixed-Integer Optimization Problems," Applied Mathematics and Computation, Vol. 212, No. 2, 2009, pp. 505-518. doi:10.1016/j.amc.2009.02.044

[29] Kumar, D., and Cesnik, C. E. S., "New Hybrid Optimization for Design of Active Twist Rotor," 54th AIAA/ASME/ASCE/AHS/ASC Structures,
Structural Dynamics, and Materials Conference, AIAA Paper 20131774, April 2013.

[30] Rohl, P. J., Dorman, P., Sutton, M., Cesnik, C. E. S., and Kumar, D., "IXGEN: A Modeling Tool for the Preliminary Design of Composite Rotor Blade," AHS Future Vertical Lift Design Conference, American Helicopter Society, San Francisco, CA, Jan. 2012.

[31] Saberi, H., Khoshlahjeh, M., Ormiston, R., and Rutkowski, M., "Overview of RCAS and Application to Advanced Rotorcraft Problems," AHS 4th Decennial Specialist Conference on Aeromechanics, American Helicopter Society, San Francisco, CA, Jan. 2004.

[32] "Model Center 10.0," Phoenix Integration, Wayne, PA, 2012.

[33] Martin, J., and Simpson, T., "Use of Kriging Models to Approximate Deterministic Computer Models," AIAA Journal, Vol. 43, No. 4, 2005 , pp. 853-863. doi: $10.2514 / 1.8650$

[34] Sacks, J., Welch, W. J., Mitchell, T. J., and Wynn, H. P., "Design and Analysis of Computer Experiments," Statistical Science, Vol. 4, No. 4, 1989, pp. 409-435.

[35] Jones, D. R., Schonlau, M., and Welch, W. J., "Efficient Global Optimization of Expensive Black Box Functions," Journal of Global Optimization, Vol. 13, No. 4, 1998, pp. 455-492. doi:10.1023/A:1008306431147

[36] Cesnik, C. E. S., Shin, S., and Wilbur, M. L., "Dynamic Response of Active Twist Rotor Blades," Smart Materials and Structures, Vol. 10 No. 1, 2001, pp. 62-76. doi:10.1088/0964-1726/10/1/306

[37] Shin, S., Cesnik, C. E. S., and Hall, S. R., "Closed Loop Control Test of the NASA/Army/MIT Active Twist Rotor for Vibration Reduction," Journal of American Helicopter Society, Vol. 50, No. 2, 2005, pp. 178 194. doi:10.4050/1.3092854

[38] Li, L., Volovoi, V., and Hodges, D., "Cross-Sectional Design of Composite Rotor Blades," Journal of the American Helicopter Society, Vol. 53, No. 1, 2008, pp. 240-251. doi:10.4050/JAHS.53.240 